\title{
Eimeria acervulina analysis for binding peptides using protein profiling for target validation
}

\author{
Gomase V.S. ${ }^{1}$, Kapoor R.A. $^{2}$, Ladak S.S. ${ }^{2}$ \\ ${ }^{1}$ School of Technology, S.R.T.M. University, Sub-Centre, Latur, 413512, India \\ ${ }^{2}$ Padmashree Dr. D.Y. Patil University, Navi Mumbai, 400614, India
}

\begin{abstract}
Eimeria acervulina is a species of Eimeria that causes coccidiosis in older poultry. Lesions are limited to anterior or first third of the small intestine. Peptide fragments of antigen protein can be used to select nonamers for use in rational vaccine design and to increase the understanding of roles of the immune system in infectious diseases. Analysis shows MHC class II binding peptides of antigen protein from Eimeria acervulina are important determinant for protection of host form parasitic infection. In this assay, we used PSSM and SVM algorithms for antigen design and predicted the binding affinity of antigen protein having 299 amino acids, which shows 291 nonamers. Binding ability prediction of antigen peptides to major histocompatibility complex (MHC) class I \& II molecules is important in vaccine development from Eimeria acervulina.
\end{abstract}

Keywords- antigen protein, epitope, PSSM, SVM, MHC, peptide vaccine

Abbreviations: Goldman, Engelberg and Steitz, (GES); major histocompatibility complex, (MHC); Position Specific Scoring Matrices, (PSSMs); Support Vector Machine, (SVM)

\section{Introduction}

Eimeria acervulina is a species of Eimeria that causes coccidiosis in older poultry. Lesions are limited to anterior or first third of the small intestine [1, 2]. Eimeria acervulina antigen peptides are most suitable for subunit vaccine development because with single epitope, the immune response can be generated in large population. This approach is based on the phenomenon of cross-protection, whereby infected with a mild strain and is protected against a more severe strain of the same. The phenotype of the resistant transgenic hosts includes fewer centers of initial infection, a delay in symptom development, and low accumulation. Antigen protein from Eimeria acervulina is necessary for new paradigm of synthetic vaccine development and target validation [3-5].

\section{Methodology}

In this research work antigenic epitopes of antigen protein from Eimeria acervulina is determined using the Gomase in 2007, Hopp and Woods, Bull \& Breeze, Eisenberg, Chou \& Fasman, and Levitt antigenicity [6-8]. The major histocompatibility complex (MHC) peptide binding of antigen protein is predicted using neural networks trained on $\mathrm{C}$ terminals of known epitopes. In analysis predicted $\mathrm{MHC} /$ peptide binding of antigen protein is a logtransformed value related to the IC50 values in $\mathrm{nM}$ units. MHC2Pred predicts peptide binders to $\mathrm{MHCl}$ and $\mathrm{MHCll}$ molecules from protein sequences or sequence alignments using Position Specific Scoring Matrices (PSSMs). Support Vector Machine (SVM) based method for prediction of promiscuous MHC class II binding peptides. SVM has been trained on the binary input of single amino acid sequence [9-14]. In addition, we predict those MHC ligands from whose C-terminal end is likely to be the result of proteosomal cleavage [15].

\section{Results and Interpretations}

We found binding of peptides to a number of different alleles using Position Specific Scoring Matrix. An antigen protein sequence is 299 residues long, having antigenic $\mathrm{MHC}$ binding peptides. MHC molecules are cell surface glycoproteins, which take active part in host immune reactions and involvement of $\mathrm{MHC}$ classI and MHC II in response to almost all antigens. PSSM based server predict the peptide binders to $\mathrm{MHCl}$ molecules of antigen protein sequence are as 11 mer_H2_Db, 10mer_H2_Db, 9mer_H2_Db, 8mer_H2_ $\mathrm{Db}$ and also peptide binders to $\mathrm{MHCll}$ molecules of antigen protein sequence as I_Ab.p, I_Ad.p, analysis found antigenic epitopes region in putative antigen protein (Table 1). We also found the SVM based MHCII-IAb peptide regions; MHCII-IAd peptide regions; MHCII-IAg7 peptide regions and $\mathrm{MHCll}-\mathrm{RT1}$.B peptide regions, which represented predicted binders from bacterial antigen protein (Table 2). The predicted binding affinity is normalized by the $1 \%$ fractil. We describe an improved method for predicting linear epitopes (Table 2). The region of maximal hydrophilicity is likely to be an antigenic site, having hydrophobic characteristics, because terminal regions of antigen protein is solvent accessible and unstructured, antibodies against those regions are also likely to recognize the native protein (Fig. 1-10). It was shown that a antigen protein is hydrophobic in nature and contains segments of low complexity and highpredicted flexibility (Fig. 4, 5). Predicted antigenic fragments can bind to MHC molecule is the first bottlenecks in vaccine design.

\section{Conclusion}

An antigen protein from Eimeria acervulina peptide nonamers are from a set of aligned peptides known to bind to a given $\mathrm{MHC}$ molecule as the predictor of MHC-peptide binding. MHCII molecules bind peptides in similar yet different modes and alignments of MHCll-ligands were obtained to be consistent with the binding mode of the peptides to their MHC class, this means the increase in affinity of $\mathrm{MHC}$ binding peptides may result in enhancement of immunogenicity of bacterial antigen protein. These predicted of antigen protein antigenic peptides to MHC class 
molecules are important in vaccine development from Eimeria acervulina

\section{References}

[1] Allen P. C. and Fetterer R. H. ( 2002) Clinical Microbiology Reviews, Vol. 15, No. 1, 58-65.

[2] Arai K. I., Lee F., Miyajima A., Miyatake S., Arai N. and Yokota T. (1990) Annu. Rev. Biochem. 59:783-836.

[3] Joshi J. Tang, Kuzma M., Wagner J., Mookerjee B., Filicko J., Carabasi M., Flomenberg N., Flomenberg P. (2009) J. Gen Virol., 90(Pt 1), 84-94.

[4] McDonald D., Stockwin L., Matzow T., Blair Zajdel M.E., Blair G.E. (1999) Gene Ther., 6(9),1512-9.

[5] Gomase V.S., Kale K.V. and Shyamkumar K. (2008) J. of Proteomics \& Bioinformatics, 1 (4), 188- 205, 2008.

[6] Gomase V.S., Kale K.V., Chikhale N.J., Changbhale S.S. (2007) Curr. Drug Discov. Technol., 4(2), 117-1215.

[7] Gomase V.S., Kale K.V. (2008) Int. J. of Applied Computing, 1(1), 39-46.
[8] Gomase V.S., Kale K.V. (2008) Int. J. of Applied Computing, 1(1), 33-38.

[9] Gomase V.S., Kale K.V. (2008) Int. J. of Information Retrieval, 1(1), 11-15.

[10] Gomase V.S., Kale K.V., Shyamkumar K. and Shankar S. (2008) ICETET 2008, IEEE Computer Society in IEEE Xplore, Los Alamitos, California, 629-634.

[11] Gomase V.S., Tandale J.P., Patil S.A., Kale K.V. (2006) 14th International Conference on Advance Computing \& Communication, Published by IEEE Computer Society in IEEE Xplore USA 614-615.

[12] Reche P.A., Glutting J.P., Reinherz E.L (2002) Hum Immun., 63, 701-709.

[13] Buus S., et al. (2003) Tissue Antigens, 62, 378-384.

[14] Nielsen M., et al. (2003) Protein Sci., 12, 1007-1017.

[15] Bhasin M. and Raghava G.P. (2005) Nucleic Acids Research, 33, W202-207. 
Table 1- PSSM based prediction of MHC ligands, from whose C-terminal end are proteosomal cleavage

\begin{tabular}{|c|c|c|c|c|c|c|c|}
\hline \multicolumn{8}{|c|}{ sites } \\
\hline MHC-I & POS. & $\mathbf{N}$ & Sequence & C & MW (Da) & Score & $\%$ OPT. \\
\hline 8mer $\mathrm{H} 2 \mathrm{Db}$ & 29 & SGG & GSRNPRNV & PSL & 880.96 & 16.638 & $31.70 \%$ \\
\hline 8mer_H2_Db & 240 & QVG & KVVNCRRV & GDM & 955.18 & 15.342 & $29.23 \%$ \\
\hline 8mer_H2 Db & 212 & GQD & VTGNFRET & RAN & 904.97 & 13.125 & $25.00 \%$ \\
\hline $8 \mathrm{mer} \mathrm{H}_{2} \mathrm{Db}$ & 147 & VDF & GSNLCRQL & CQM & 872.01 & 13.087 & $24.93 \%$ \\
\hline 8mer_H2_Db & 205 & QGH & IVFNGQDV & TGN & 872.97 & 11.814 & $22.51 \%$ \\
\hline 8mer_H2_Db & 172 & ATL & PNGEAVTL & PGS & 781.86 & 11.772 & $22.43 \%$ \\
\hline $9 \mathrm{mer} \mathrm{H} 2 \mathrm{Db}$ & 31 & GGS & RNPRNVPSL & HYF & 1034.19 & 14.901 & $29.59 \%$ \\
\hline $9 \mathrm{mer} \mathrm{H} 2 \mathrm{Db}$ & 169 & SVQ & ATLPNGEAV & TLP & 852.94 & 12.849 & $25.51 \%$ \\
\hline 9mer_H2_Db & 46 & ISV & NHQCNFSSF & SWS & 1065.13 & 12.593 & $25.00 \%$ \\
\hline 9mer_H2_Db & 132 & PSR & FGVDLVDCL & KVE & 962.13 & 12.374 & $24.57 \%$ \\
\hline 9mer_H2_Db & 42 & LHY & FISVNHQCN & FSS & 1043.16 & 12.029 & $23.88 \%$ \\
\hline 9mer $\mathrm{H} 2 \mathrm{Db}$ & 239 & SQV & GKVVNCRRV & GDM & 1012.23 & 10.142 & $20.14 \%$ \\
\hline 10mer_H2_Db & 46 & ISV & NHQCNFSSFS & WSV & 1152.21 & 15.72 & $26.71 \%$ \\
\hline $10 \mathrm{mer} H 2 \mathrm{Db}$ & 127 & FKP & SAPSRFGVDL & VDC & 1030.16 & 12.455 & $21.16 \%$ \\
\hline 10mer_H2_Db & 49 & $\mathrm{NHQ}$ & CNFSSFSWSV & NTR & 1122.26 & 10.879 & $18.48 \%$ \\
\hline 10mer_H2_Db & 204 & $\overline{D Q G}$ & HIVFNGQDVT & GNF & 1111.21 & 10.442 & $17.74 \%$ \\
\hline $10 \mathrm{mer} \mathrm{H}_{2} \mathrm{Db}$ & 170 & VQA & TLPNGEAVTL & PGS & 996.12 & 9.781 & $16.62 \%$ \\
\hline 10mer $\mathrm{H} 2 \mathrm{Db}$ & 31 & GGS & RNPRNVPSLH & YFI & 1171.33 & 9.391 & $15.96 \%$ \\
\hline $11 \mathrm{mer} \_\mathrm{H} 2 \_\mathrm{Db}$ & 218 & NFR & ETRANFRFTKL & LDI & 1364.57 & 11.235 & $14.13 \%$ \\
\hline 11mer_H2_Db & 105 & VLR & RSALEKNAVMW & PEN & 1263.51 & 7.985 & $10.04 \%$ \\
\hline 11mer_H2_Db & 239 & SQV & GKVVNCRRVGD & MHV & 1184.37 & 7.816 & $9.83 \%$ \\
\hline 11mer_H2_Db & 202 & FGD & QGHIVFNGQDV & TGN & 1195.29 & 6.213 & $7.82 \%$ \\
\hline 11mer_H2_Db & 169 & SVQ & ATLPNGEAVTL & PGS & 1067.2 & 5.98 & $7.52 \%$ \\
\hline $11 \mathrm{mer}$ & 140 & VDC & LKVEVDFGSNL & $\mathrm{CRQ}$ & 1202.37 & 3.418 & $4.30 \%$ \\
\hline
\end{tabular}

Table 2- SVM based prediction of promiscuous MHC class II binding peptides from antigen protein

\begin{tabular}{|l|l|l|l|l|}
\hline $\begin{array}{l}\text { MHC } \\
\text { ALLELE }\end{array}$ & Rank & Sequence & $\begin{array}{l}\text { Residue } \\
\text { No. }\end{array}$ & $\begin{array}{l}\text { Peptide } \\
\text { Score }\end{array}$ \\
\hline I-Ab & 1 & GLTSRFNKH & 2 & 0.869 \\
\hline I-Ab & 2 & RMTTNLGRN & 271 & 0.815 \\
\hline I-Ab & 3 & PVLRRSALE & 101 & 0.744 \\
\hline I-Ab & 4 & VVTWGSVPK & 280 & 0.737 \\
\hline I-Ad & 1 & SESLVSVAT & 13 & 0.702 \\
\hline I-Ad & 2 & HAGSLPVLR & 96 & 0.698 \\
\hline I-Ad & 3 & PGSKEGAAF & 67 & 0.633 \\
\hline I-Ad & 4 & GSNSVQATL & 163 & 0.627 \\
\hline I-Ag7 & 1 & EGAAFAAST & 71 & 1.792 \\
\hline I-Ag7 & 2 & KEGAAFAAS & 70 & 1.561 \\
\hline I-Ag7 & 3 & RETRANFRF & 217 & 1.548 \\
\hline I-Ag7 & 4 & QPFADHEEL & 82 & 1.489 \\
\hline RT1.B & 1 & AFAASTRTQ & 74 & 1.220 \\
\hline RT1.B & 2 & LDIQSAASQ & 229 & 0.868 \\
\hline RT1.B & 3 & RTQPFADHE & 80 & 0.839 \\
\hline RT1.B & 4 & RFTKLLDIQ & 224 & 0.618 \\
\hline
\end{tabular}




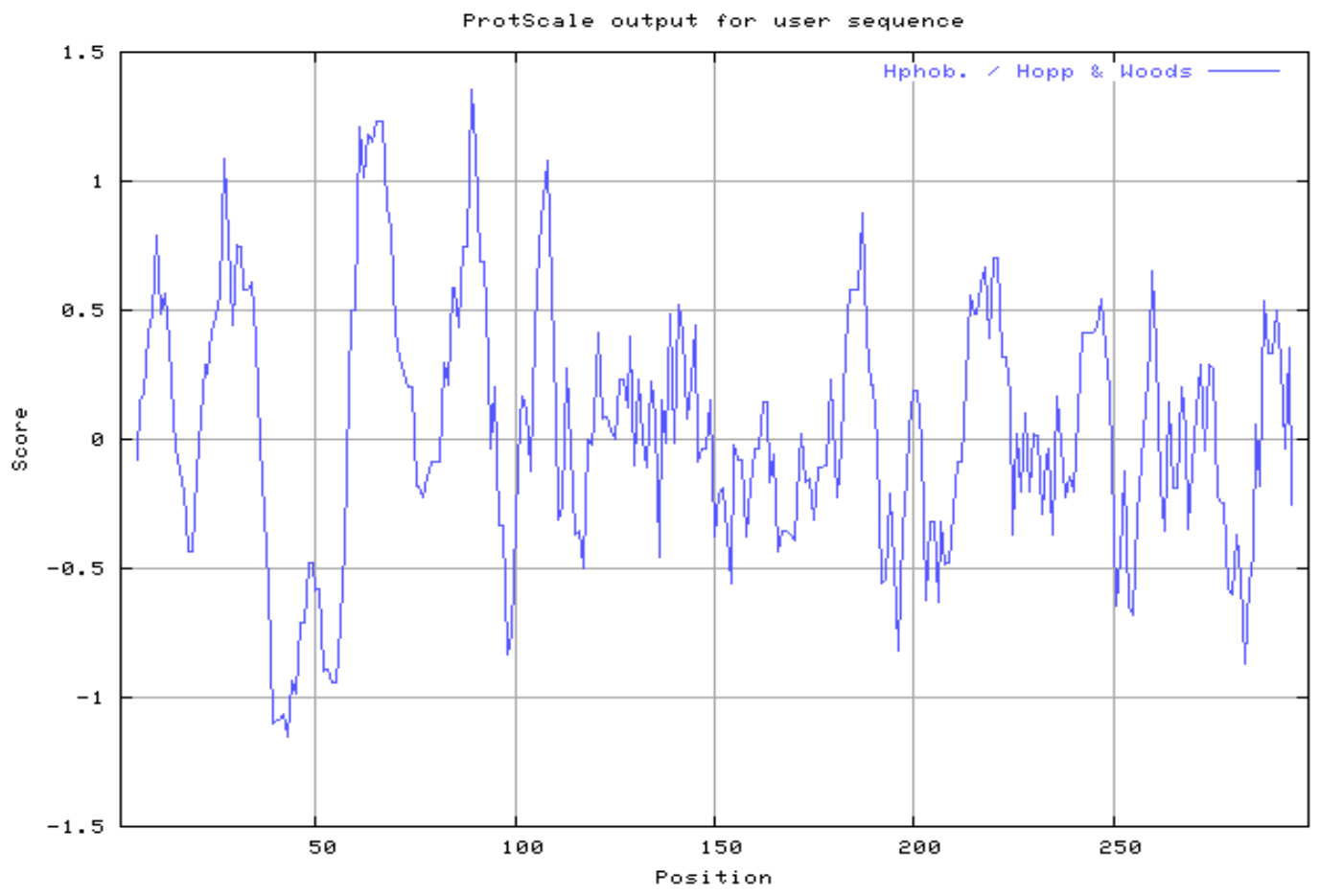

Fig.1-Hydrophobicity plot of antigen protein by Hopp \& Woods scale

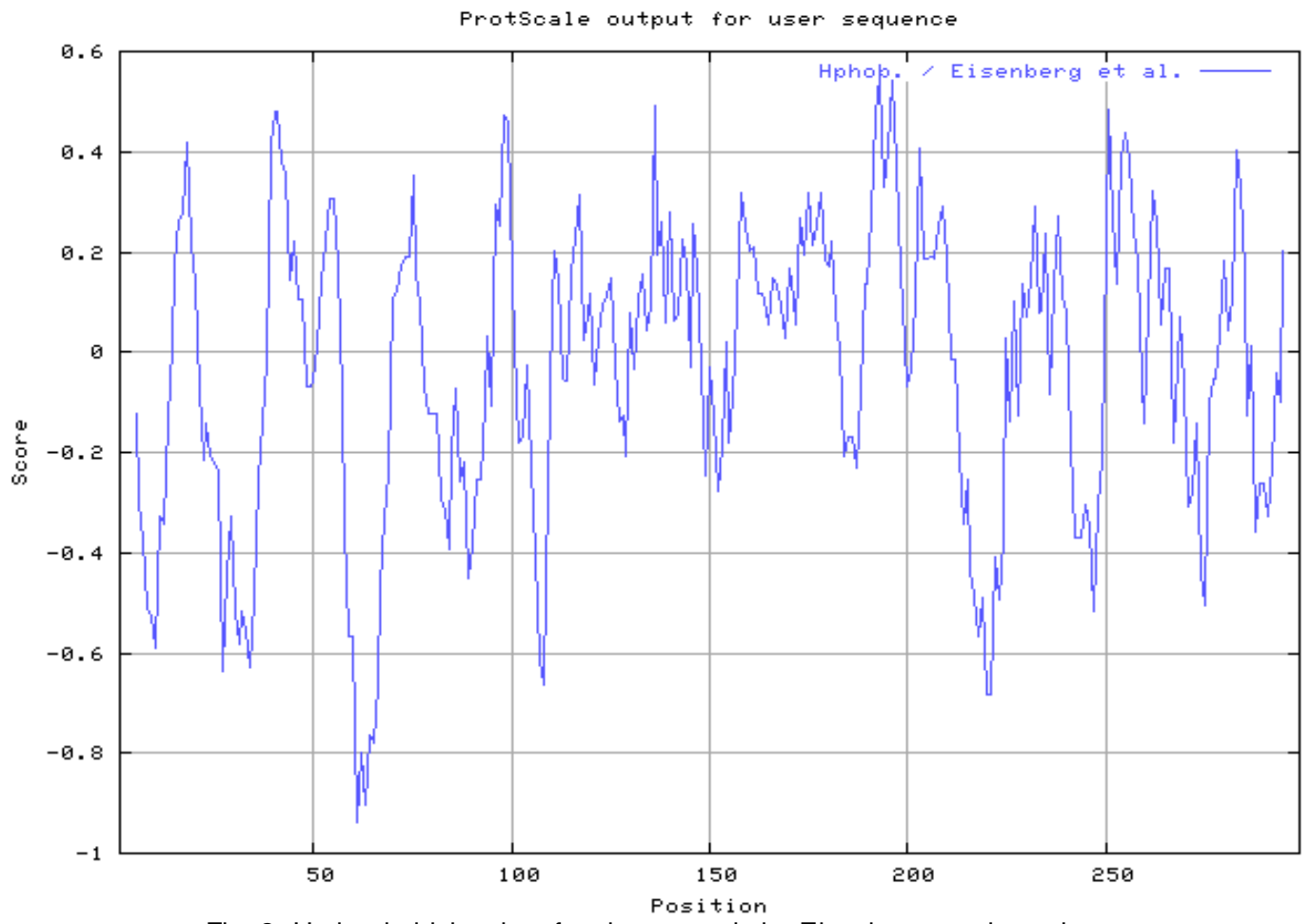

Fig. 2- Hydrophobicity plot of antigen protein by Eisenberg, et al., scale 


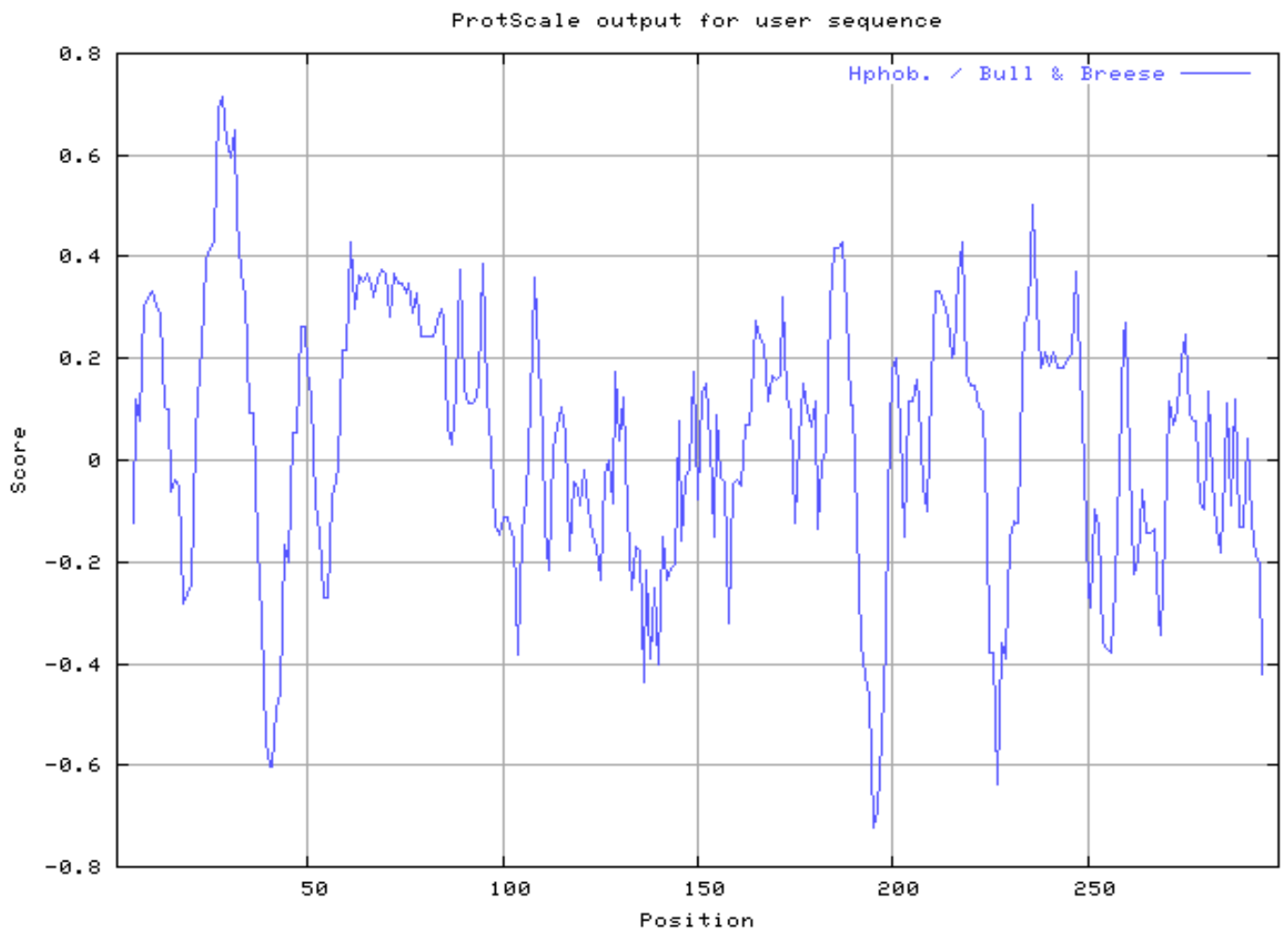

Fig. 3-Hydrophobicity plot of antigen protein by Bull \& Breese scale

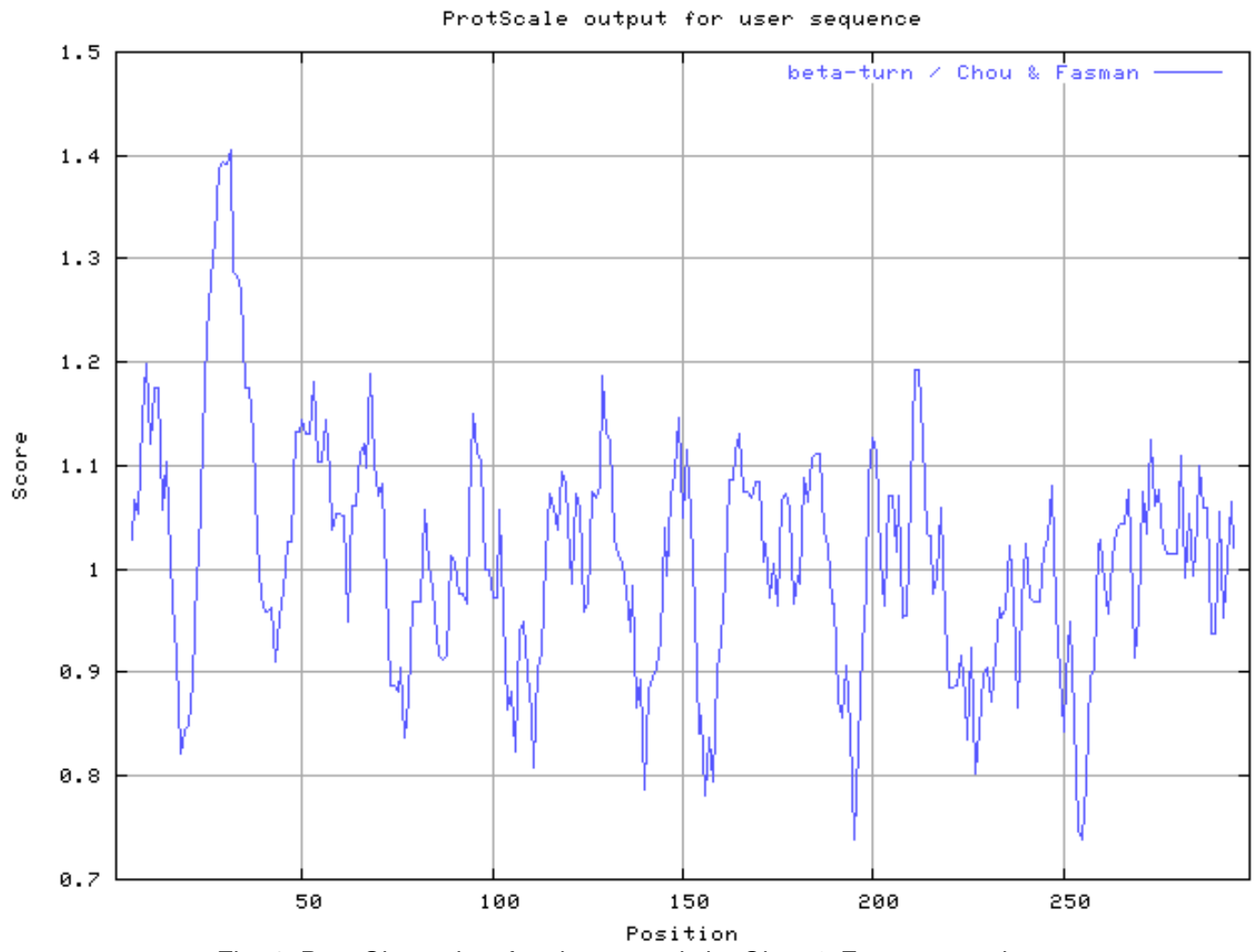

Fig. 4- Beta Sheet plot of antigen protein by Chou \& Fasman., scale 


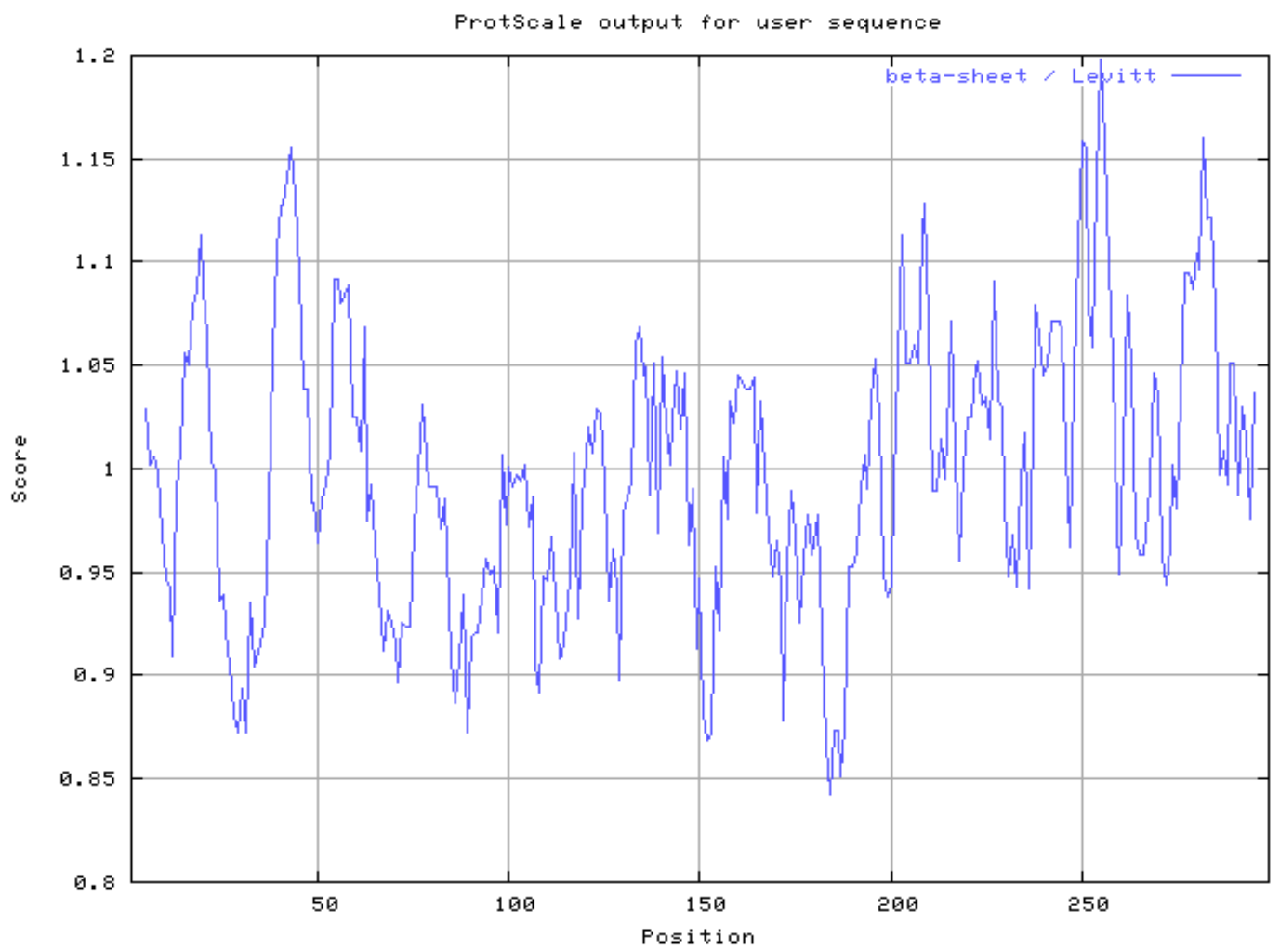

Fig. 5- Beta Sheet plot of antigen protein by Levitt, scale

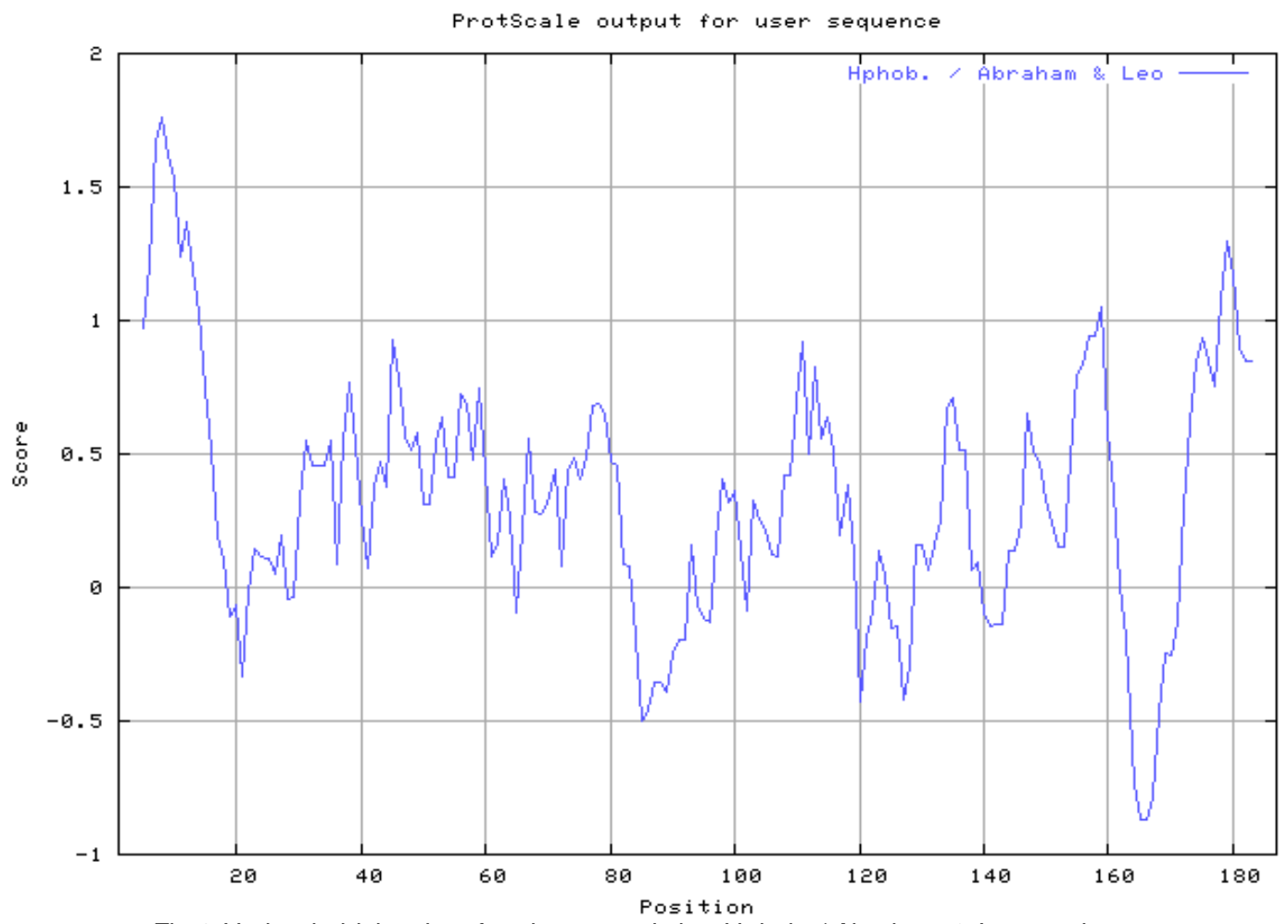

Fig.6-Hydrophobicity plot of antigen protein by Hphob. / Abraham \& Leo, scale 


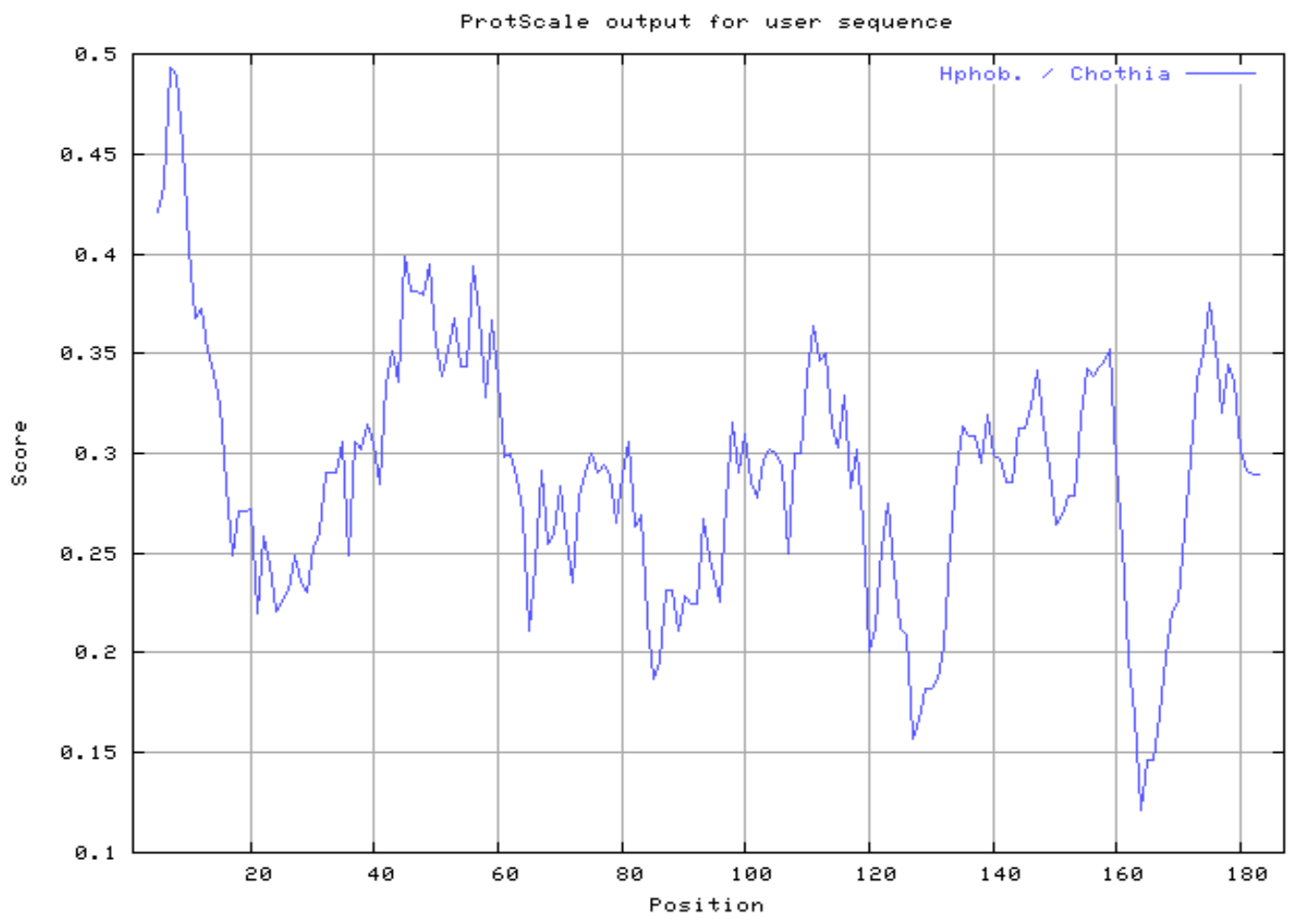

Fig.7-Hydrophobicity plot of antigen protein by Chothia, scale

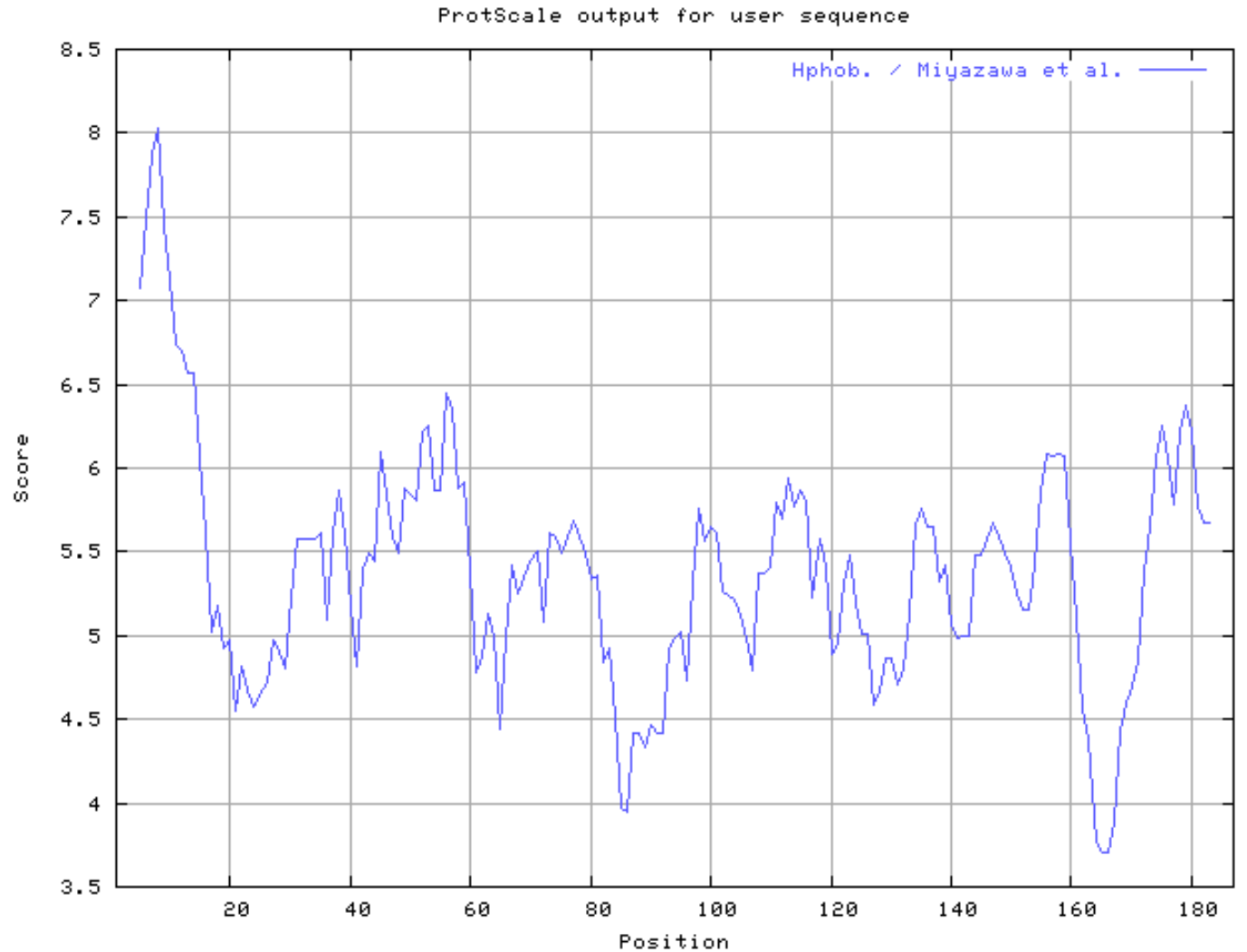

Fig.8-Hydrophobicity plot of antigen protein by Hphob. / Miyazawa et al., scale 


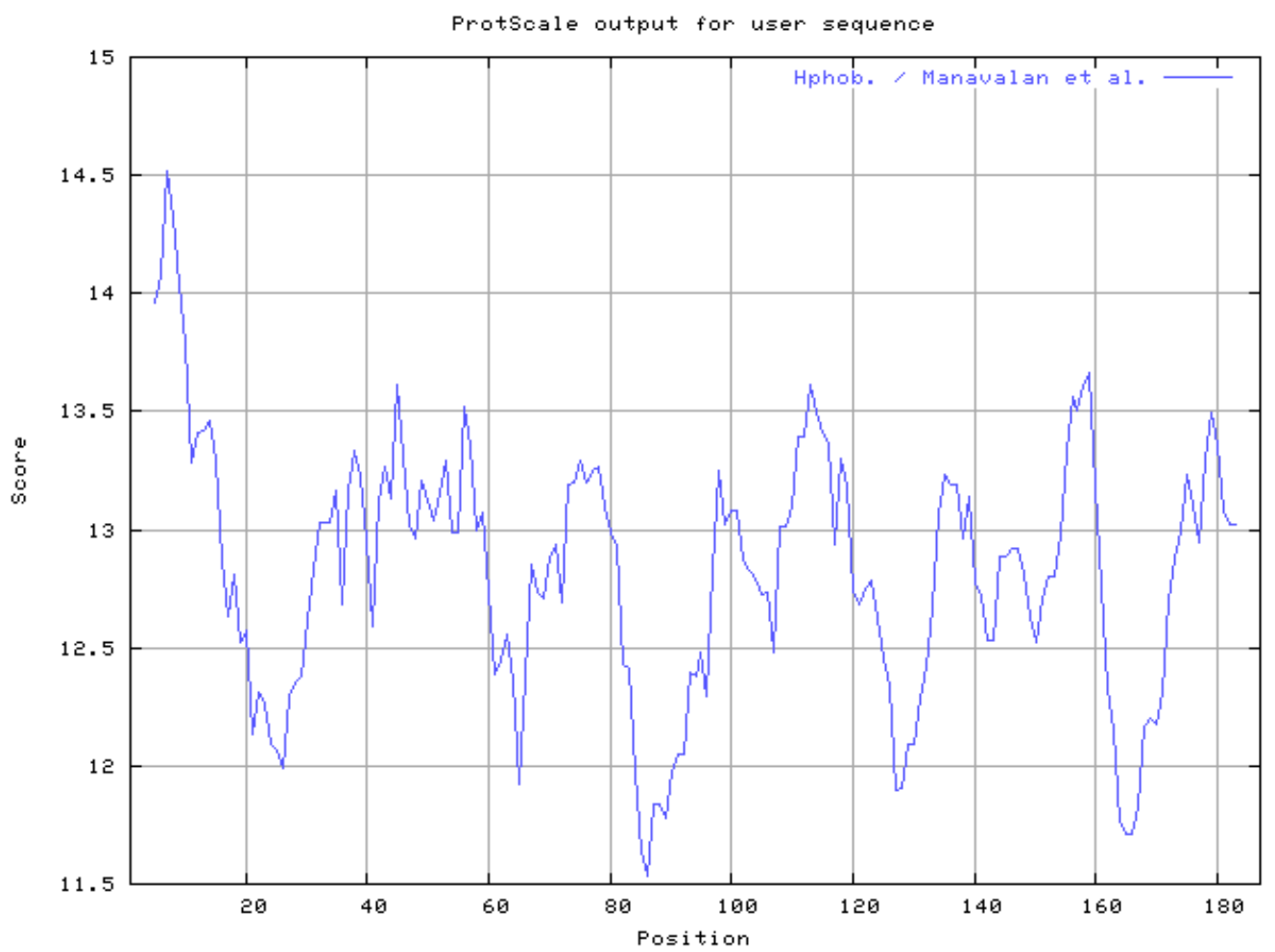

Fig.9-Hydrophobicity plot of antigen protein by Manavalan et al., scale

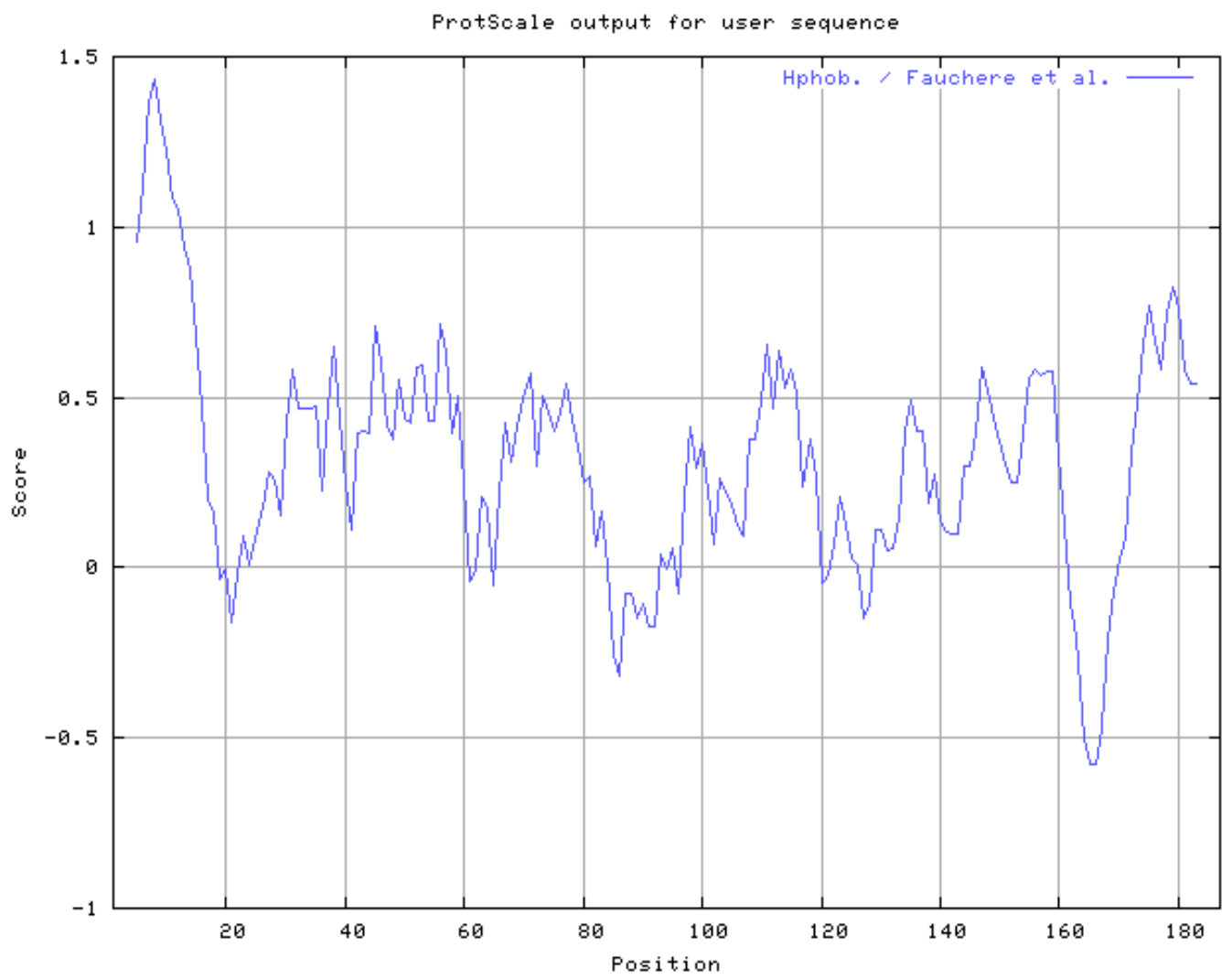

Fig.10-Hydrophobicity plot of antigen protein by Fauchere et al., scale 